\title{
Phthalates and asthma in children and adults: US NHANES 2007-2012
}

\author{
Chinonso Christian Odebeatu ${ }^{1} \cdot$ Timothy Taylor $^{1}$ (D) $\cdot$ Lora E. Fleming ${ }^{1} \cdot$ Nicholas J. Osborne $^{1,2,3}$
}

Received: 22 March 2019 / Accepted: 16 July 2019 / Published online: 31 July 2019

(C) The Author(s) 2019

\begin{abstract}
Environmental exposure to phthalates may contribute to an increased risk of asthma in children and adults. We aimed to assess the direction and strength of the association between urinary phthalates metabolites and current asthma in children and adults that participated in the National Health and Nutrition Examination Survey (NHANES) 2007-2012. Data on ten urinary phthalate metabolites, self-reported questionnaires, spirometry measures, and covariates were obtained from 7765 participants (28.1\% were children aged 6-17 years) taking part in the NHANES 2007-2012. Asthma was assessed using self-reported questionnaires for children and adults, and via spirometry measures for adults alone. We used crude and adjusted logistic regression models to estimate the odds ratios (ORs) and 95\% confidence interval (CI) per one $\log _{10}$ unit change in the concentration of phthalate metabolites. We further modeled the effect modification by sex. Out of 10 metabolites, only mono-benzyl phthalate (MBzP) was positively associated with the prevalence of self-reported asthma in children, after adjusting for a range of potential confounders (odds ratio 1.54 ; 95\% confidence interval 1.05-2.27). No significant relationship was observed for adults. The association of mono-ethyl phthalate (MEP) was modified by sex, with significantly increased odds of asthma among males [boys $(2.00 ; 1.14-3.51)$; adult males $(1.32 ; 1.04-1.69)$ ]. While no other phthalates showed a positive relationship with current asthma in males, mono-(carboxynonyl) phthalate (MCNP) and mono-(3-carboxylpropyl) phthalate (MCPP) were inversely associated with spirometrically defined asthma in adult females. A sex-specific relationship in adults was evident when spirometry, but not self-reported measures were used to define asthma. We found no clear association between exposure to phthalates and current asthma, except for a significant relationship between MBzP metabolites and self-reported asthma in children. As a result, exposure to phthalates and asthma development and/or exacerbations remains controversial, suggesting a need for a well-designed longitudinal study.
\end{abstract}

Keywords Phthalate metabolites $\cdot$ Mono-benzyl phthalate $\cdot$ Childhood asthma $\cdot$ Adult asthma $\cdot$ NHANES

Responsible editor: Philippe Garrigues

Electronic supplementary material The online version of this article (https://doi.org/10.1007/s11356-019-06003-2) contains supplementary material, which is available to authorized users.

Timothy Taylor timothy.j.taylor@exeter.ac.uk

Nicholas J. Osborne n.osborne@uq.edu.au

Chinonso Christian Odebeatu chinonsoodebeatu@gmail.com

Lora E. Fleming

1.e.fleming@exeter.ac.uk
1 European Centre for Environment and Human Health, Knowledge Spa, Royal Cornwall Hospital, University of Exeter Medical School, Truro, Cornwall TR1 3HD, UK

2 School of Public Health and Community Medicine, University of New South Wales, Kensington, Sydney 2052, Australia

3 School of Public Health, The University of Queensland, Herston, Queensland 4006, Australia 


\section{Introduction}

For the past two decades, the prevalence of asthma has substantially increased in both the developed and developing countries (Osborne et al. 2017). The International Study of Asthma and Allergies in Childhood (ISAAC) study demonstrated that across 37 countries including the US and the UK, the average prevalence of asthma in 2006 amongst children aged 6-7 years was $12.6 \%$ (Asher et al. 2006). The Global Burden of Disease attributed to asthma is predicted to be about 11 million years of life lost (YLLs) and 25 million disabilityadjusted life years (DALYs) per year (Osborne et al. 2017).

Asthma is a common chronic disease in children and adults characterised by airway inflammation and increased mucus production-leading to airway obstruction (Khalili et al. 2018). It is estimated by the US Centers for Disease Control and Prevention (CDC) that $6.8 \%$ of US working adults have current asthma - defined as having had at least one asthma attack or visit the emergency department (ED) for asthma in the past 12 months (Mazurek and Syamlal 2018). The disease is a potential threat to children's growth and development including their educational achievement (Nurmagambetov et al. 2018). In 2017, the prevalence of asthma was reported in approximately 6.2 million children in the US-about $8.4 \%$ of children under the age of 18 (CDC 2017). The US annual economic costs associated with asthma have been estimated at $\$ 81$ billion for 2013, including treatment costs and mortality costs valued using the value of statistical life and lost work and school days (Nurmagambetov et al. 2018). The root causes of asthma have not been fully elucidated, but genetic predisposition, and environmental factors including allergens and chemicals (such as phthalates) as well as geneenvironment interactions, have been suggested as important risk factors for asthma pathogenesis and exacerbations (Wang et al. 2015; Sordillo et al. 2015; Surdu et al. 2006).

Phthalates are synthetic chemicals produced by reacting phthalic anhydride with different chain lengths of alcohol(s) which may vary from single chain alcohol (such as methanol) to multiple chain alcohol (such as tridecyl alcohol) (Benjamin et al. 2017). They are mainly classified into two types - high (HMW) and low molecular weight (LMW) phthalates - and their uses may in part depend on their molecular weight (Table 1) (Braun et al. 2013; Benjamin et al. 2017). Phthalates are omnipresent and are not covalently bound to the consumer products; they easily leach out and make their way to the environment (Tsai et al. 2012). Humans are exposed to these chemicals through several routes of exposure including water, breathing air, dermal contact, during medical treatment and, importantly, via food (Benjamin et al. 2017).

Although phthalates are easily bio-transformed and excreted (leading to lesser bioaccumulation), regular exposure in humans may exacerbate the risk of developing asthma or prolong its prevalence by binding with and activating peroxisome proliferator-activated receptors (PPARs) which mediate antiinflammatory effects in the lungs and immune systems (Bølling et al. 2013); increasing the proliferation of the bronchial muscle cells which may lead to airways remodelling (Kuo et al. 2011); promoting the production of proinflammatory cytokines IL- 6 and IL-8 in the airway epithelial cells (Jepsen et al. 2004); and/or; acting as an adjuvants by enhancing macrophage production of inflammatory cytokines and chemokines (Nishioka et al. 2012).

Several epidemiological studies have demonstrated that regular exposure to phthalates is associated with an increased risk of non-communicable chronic diseases including cardiovascular diseases and diabetes (Dong et al. 2017; Bai et al. 2017). Limited information is known about the association between phthalates exposure and the prevalence of asthma (Benjamin et al. 2017), with available evidence producing inconsistent results. A meta-analysis demonstrated that postnatal exposure to di-(2-ethylhexyl) phthalate (DEHP) and butylbenzyl phthalate (BBzP) from dust and prenatal urinary mono-benzyl phthalate $(\mathrm{MBz})$ were significantly associated with childhood asthma ( $\mathrm{Li}$ et al. 2017).

In contrast, a recent study has shown that both LMW and HMW phthalates (including DEHP) were not associated with the report of doctor-diagnosed asthma (Vernet et al. 2017). Previous research found that the urinary concentration of MBzP metabolite was associated with self-reported asthma in adults but not in children (Hoppin et al. 2013). These inconsistencies need to be addressed with more research into the potential association between phthalates and asthma in children and adults using a large cross-sectional secondary data and better outcome measures (for example spirometry and questionnaire data).

In addition, the development and/or exacerbation of asthma may be sex-specific. Whilst the prevalence of asthma, in general, is greater in females than in males (CDC 2008), investigation at a specific time point revealed otherwise. Before age 13-14 years, the incidence and prevalence of asthma with increased wheeze, use of asthma medications and serum $\operatorname{IgE}$ level are greater among boys than among girls (Wijga et al. 2011; Almqvist et al. 2008; Bjornson and Mitchell 2000). By contrast, studies through puberty and beyond have found a greater increase in the incidence and prevalence of asthma among adolescent and young adult females (CDC 2008; De Marco et al. 2000). Importantly, a prospective cohort study demonstrated that the relationship between phthalates and asthma may be modified by sex (Buckley et al. 2018), with 5 -year-old boys at increased odds of asthma occurrence following exposures to mono-(2-ethylhexyl) phthalate (MEHP) and mono-ethyl phthalate (MEP) (Ku et al. 2015).

In the current study, we polled the National Health and Nutrition Examination Survey (NHANES) 2007-2012 data to examine the direction and strength of the association between urinary phthalate metabolites and current asthma in 


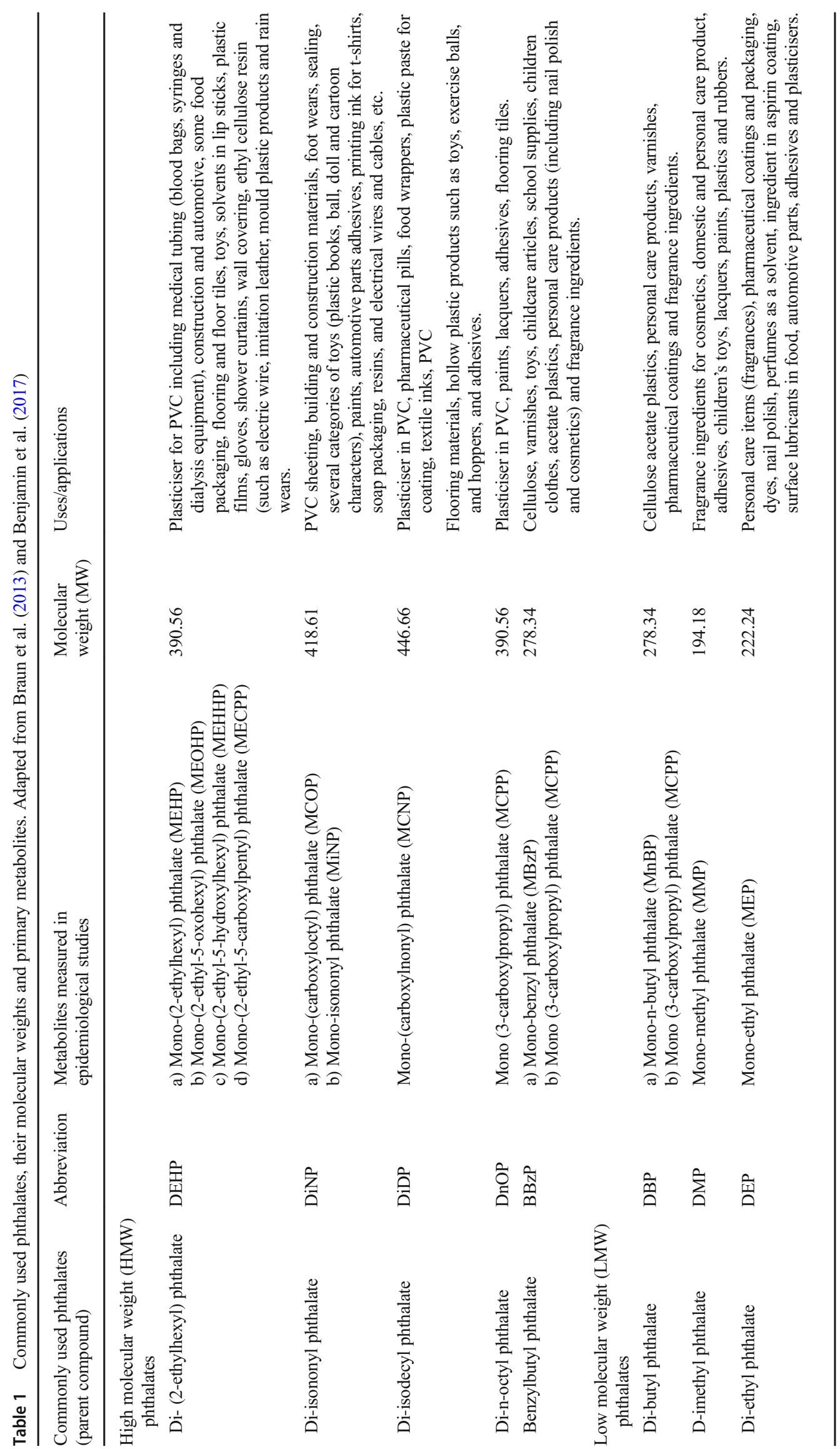


children and adults. As a secondary aim, we stratified the data based on the participant sex, to investigate whether the effect measure was modified by sex in both children and adults.

\section{Methods}

\section{Study population}

NHANES is a nationally representative, multi-stage, population-based, cross-sectional study carried out by the US National Centre for Health Statistics (NCHS). It was designed to assess the health and nutritional status of civilian, noninstitutionalised children and adults in the US. Respondents for our study were children aged between 6 and 17 years, and adults aged 18 and 79 years, who were randomly selected by the NHANES for urinary phthalates measurement; and who had complete information on self-reported questionnaires, spirometry and confounding variables. Participants aged 80 years and over were excluded in order to reduce biases resulting from the non-representation of the older adults who are institutionalised after 80 years.

Data were pooled from three independent cross-sectional waves (2007-2008, 2009-2010, and 2011-2012), providing an initial total sample of 30,442 participants $(11,823$ children and 18,619 adults). Urinary phthalate concentrations were determined for 7765 subsets (2180 children and 5585 adults); therefore, only these participants were used for analysis. All selected participants provided informed consent in writing during the period of recruitment (NHANES 2017).

\section{Measurement of phthalate metabolites}

Phthalate metabolites were measured in a spot urine sample of a randomly selected one third sub-sample of the study respondents. These collected samples were frozen at the temperature of $-20^{\circ} \mathrm{C}$ and shipped to the division of Environmental Health Laboratory Sciences, National Centre for Environmental Health, CDC for the analysis of various phthalate metabolites. In order to reduce the possibility of exposure misclassification (James-Todd et al. 2016), phthalate metabolites were measured instead of their parent compound. A full description of the analytical methods employed for the measurement of phthalates metabolites have been described elsewhere (Laboratory Procedure Manual 2013).

A combination of phthalate metabolites that have been previously studied and those that were measured in all the three cross-sectional waves, with more than $60 \%$ of the sample concentrations at or above the limit of detection (LOD) (JamesTodd et al. 2016) were selected for this project. These included ten (10) phthalate metabolites: mono-(carboxynonyl) phthalate (MCNP), mono-(2-ethyl-5-carboxypentyl) phthalate (MECPP), MEHP, mono-(2-ethyl-5-hydroxylhexyl) phthalate
(MEHHP), mono-(2-ethyl-5-oxohexyl) phthalate (MEOHP), mono-n-butyl phthalate (MnBP), mono-iso-butyl phthalate (MiBP), MBzP, MEP and mono-(3-carboxylpropyl) phthalate (MCPP).

Given that the LOD for phthalate metabolites differed across each survey cycle, the maximum limit of detection $\left(\mathrm{LOD}_{\max }\right)$ was used to standardise each phthalate detection limits in the three cross-sectional waves (Varshavsky et al. 2018). Thus, all concentrations below the $\mathrm{LOD}_{\max }$ were substituted with the value of $\mathrm{LOD}_{\max }$ divided by the square root of two (Varshavsky et al. 2018).

\section{Asthma data}

\section{Self-reported questionnaire data}

NHANES collected information on asthma and associated symptoms using a self-administered questionnaire completed at the NHANES clinic visit. Following the recommendation from the European birth cohort study (Carlsen et al. 2012), current asthma was defined by respondents giving a positive response to both questions: "Has a doctor or other health professional ever told you that you have asthma?" and "In the past 12 months (have you/has SP) had wheezing or whistling in (your/his/her) chest?"

\section{Spirometry data}

Spirometry data were available in all cross-sectional waves and were also used for asthma determination. Participants aged 6 to 79 years were considered eligible for spirometry testing. Respondents were excluded if they: had current chest pain or physical problems with forceful expiration; had recent chest, eye or abdominal surgery; had a heart problem (such as heart attack), stroke or tuberculosis; were taking supplementary oxygen; had a collapsed lung or detached retina; had painful ear problems or had coughed up blood recently (NHANES 2014).

Spirometry testing for eligible participants was performed following the procedures recommended by the American Thoracic Society (ATS). The protocol and procedures for spirometry testing have been described elsewhere (NHANES 2008). The baseline spirometry results of forced expiratory volume in $1 \mathrm{~s}\left(\mathrm{FEV}_{1}\right)$, forced vital capacity (FVC) and $\mathrm{FEV}_{1} / \mathrm{FVC} \%$ were determined by adopting a normal equation for spirometry parameters of the US population which takes into account each respondent's age, sex, weight, height and race/ethnicity (NHANES 2014).

Based on the guidelines set from the International Consensus Statement between the ATS and the European Respiratory Society (ERS) which suggest the presence of airflow obstruction when the FEV1/FVC ratio was less than $70 \%$ (Cerveri et al. 2008), current untreated asthma was defined via 
spirometry results as respondents with an FEV1/FVC of $<$ $70 \%$ (Abo-Zaid et al. 2018). Analyses using self-reported but not with spirometry data were performed for children. This is because accuracy and precision suffer in spirometry testing involving children (Murray et al. 2016).

\section{Confounding variables}

Information on covariates was obtained from the NHANES. These covariates were determined using the self-reported questionnaire, physical examination, and laboratory measurements. Age, sex, race/ethnicity and poverty status (which serves as a proxy for socioeconomic status (SES)) were ascertained via questionnaire. Poverty status was defined by the poverty income ratio (PIR) which was calculated by dividing the family income by the poverty guidelines of a specific survey year. Race/ethnicity was classified as "nonHispanic white" (referent group), "non-Hispanic black", "Mexican-American," and "Other".

Waist circumference in centimetres $(\mathrm{cm})$ was used as a measure of overweight since it gives a better measure of obesity-related health risks than body mass index (BMI) (Janssen et al. 2004). Urinary creatinine concentrations were measured using Roche/Hitachi Modular P chemistry analyser and Synchron CX3 clinical analyser (Beckman, CA, USA). Serum cotinine level (a biomarker for smoking status) was categorised as $<$ LOD $(<0.015)$ nanogram $/ \mathrm{ml}(\mathrm{ng} / \mathrm{ml})$ (referent), low levels $(\geq 0.015-10 \mathrm{ng} / \mathrm{ml})$ and high levels $(\geq$ $10 \mathrm{ng} / \mathrm{ml})$.

\section{Statistical analysis}

The Spearman's rank correlation coefficient was used to examine phthalate metabolite correlation. Phthalate metabolite was considered to have a strong correlation with a Spearman's correlation coefficient $\left(r_{s}\right)$ greater than or equal to $0.7\left(r_{s} \geq\right.$ 0.7). MEHP (a primary metabolite) and MECPP, MEHHP and MEOHP (secondary metabolites) of DEHP were strongly correlated with one another (with a value of $r_{s}$ between 0.730.98) (Additional file 1: Table S1). Therefore, these metabolites were not separately analysed given their strong correlation and common source; the molar sum of DEHP denoted as " $\Sigma$ DEHP", was used instead (Hoppin et al. 2013).

Sampling weights, stratification and clustering provided in the NHANES study were applied to all statistical analysis in order to account for the complex, multistage sampling design employed in the selection of the representative noninstitutionalised US population as well as obtaining accurate estimates that will not overstate the statistical significance. Following the NHANES analytical guidelines (Johnson et al. 2013), a new sampling weight for the combined survey cycle was constructed by dividing the 2-year weights for each cycle by 3 which was applied to the data via the Stata command [svyset] prior to analysis.

Descriptive statistics (weighted means, standard deviation, weighted percentages and $95 \%$ confidence interval $(\mathrm{CI})$ ) were used to describe the demographics of all children and adults and their respective subsets with measured urinary phthalate metabolite concentrations. The distribution of urinary phthalate metabolites were presented for both children and adults using weighted geometric means, 95\% CI and percentiles.

Logistic regression models (models 1 and 2) were used to determine the cross-sectional measure of the association between urinary phthalate metabolites (continuous) and current asthma (dichotomous outcome) by estimating the odds ratios (ORs) and 95\% CIs per one $\log _{10}$ unit change in the concentration of phthalate metabolites. Model 1 was presented as unadjusted ORs and 95\% CI. Model 2 was adjusted for urinary creatinine ( $\log _{10}$ transformed, continuous) in addition to other potential confounding variables.

Potential confounders included in this analysis were those suggested as being linked with phthalate metabolites and/or asthma (Hoppin et al. 2013; James-Todd et al. 2016; Gascon et al. 2015; Buckley et al. 2018). These variables included age, sex, race/ethnicity, waist circumference, PIR, cotinine and urinary creatinine. The analysis was further stratified by sex for both children and adults by applying similar statistical modeling.

In order to assess the robustness of our findings, a sensitivity analysis was performed. Exposure-response relationships were examined by modeling the associations between tertiles of phthalate creatinine-corrected concentrations and asthma, with the lowest tertile considered as the reference category (Buckley et al. 2018). Tertiles were categorised separately for children and adults such that each tertile contained an equal number of participants. While results for each phthalate metabolite were presented as crude and adjusted ORs and 95\% CIs, only adjusted models were shown for effect modifications by sex and sensitivity analyses. All statistical analyses were conducted using STATA version 15.0 (College Station, TX, USA).

\section{Results}

The demographic characteristics of all children $(n=11,823)$ and the subset with measured urinary phthalate concentrations $(n=2180)$, who participated in the NHANES 2007-2012 are shown in Table 2. Approximately $8 \%$ of children in both groups had self-reported asthma. With spirometry measures, the proportion of respondents with current asthma dropped to less than $2 \%$. The weighted proportions of all children belonging to any race or living below the poverty threshold [povertyto-income ratio (PIR)] were somewhat similar to those with measured phthalate metabolites. 
Table 2 Demographic and asthma status for all children and subsets sampled for phthalate concentrations, NHANES $2007-2012$

Children aged 6 to $<18$ years

\begin{tabular}{|c|c|c|}
\hline Characteristics & All participants $(n=11823)$ & $\begin{array}{l}\text { Participants sampled for phthalate } \\
\text { concentrations }(n=2180)\end{array}$ \\
\hline Age at screening (years), weighted mean (SD, 95\% CI) & $8.6(5.2,8.44-8.74)$ & $11.5(3.4,11.27-11.71)$ \\
\hline \multicolumn{3}{|l|}{ Sex } \\
\hline Male, weighted $\%(n, 95 \% \mathrm{CI})$ & $50.8(6037,49.26-52.25)$ & $50.1(1095,47.09-53.00)$ \\
\hline Female, weighted $\%(n, 95 \% \mathrm{CI})$ & $49.2(5786,47.75-50.74)$ & $49.9(1085,46.99-52.91)$ \\
\hline \multicolumn{3}{|l|}{ Race/ethnicity, weighted \% ( $n, 95 \% \mathrm{CI})$} \\
\hline Non-Hispanic whites & $55.5(3646,50.57-60.39)$ & $56.1(619,50.38-61.62)$ \\
\hline Non-Hispanic Blacks & $14.3(2801,11.99-17.04)$ & $14.7(551,12.13-17.73)$ \\
\hline Mexican American Hispanic & $15.0(2983,12.04-18.63)$ & $14.8(537,11.48-18.77)$ \\
\hline Others & $15.1(2575,12.90-17.58)$ & $14.4(473,11.74-17.66)$ \\
\hline Waist circumference $(\mathrm{cm})$, weighted mean $(\mathrm{SD}, 95 \% \mathrm{CI})$ & $67.8(16.2,67.25-68.34)$ & $73.1(15.4,72.10-73.99)$ \\
\hline \multicolumn{3}{|l|}{ Family income-to-poverty ratio (PIR), weighted \% (n, 95\% CI) } \\
\hline Below poverty $(\mathrm{PIR}<1)$, weighted $\%(n, 95 \% \mathrm{CI})$ & $24.4(3823,21.97-27.03)$ & $23.7(668,20.85-26.82)$ \\
\hline At or above poverty (PIR $\geq 1)$ & $75.6(7052,72.97-78.03)$ & $76.3(1333,73.18-79.15)$ \\
\hline Urinary creatinine $(\mathrm{mg} / \mathrm{dL})$, weighted mean $(\mathrm{SD}, 95 \% \mathrm{CI})$ & $119.2(74.2,114.76-123.69)$ & $118.6(75.3,113.76-123.36)$ \\
\hline \multicolumn{3}{|l|}{ Cotinine levels $(\mathrm{ng} / \mathrm{mL})$, weighted $\%(n, 95 \% \mathrm{CI})$} \\
\hline$<\operatorname{LOD}(<0.015)$ & $25.9(1554,23.03-29.13)$ & $26.8(457,22.94-30.99)$ \\
\hline Low $(\geq 0.015$ to $<10)$ & $70.4(4855,67.15-73.42)$ & $68.7(1322,64.72-72.47)$ \\
\hline $\operatorname{High}(\geq 10)$ & $3.7(184,2.96-4.50)$ & $4.5(63,3.18-6.33)$ \\
\hline \multicolumn{3}{|c|}{ Current asthma based on self-reported questionnaire, weighted $\%(n, 95 \% \mathrm{CI})$} \\
\hline Yes & $7.6(800,7.13-8.14)$ & $8.1(177,6.80-9.71)$ \\
\hline No & $92.4(9700,91.86-92.87)$ & $91.9(2003,90.29-93.20)$ \\
\hline \multicolumn{3}{|c|}{ Current asthma based on spirometry $\mathrm{FEV}_{1} / \mathrm{FVC}$ cutoff, weighted $\%(n, 95 \% \mathrm{CI})$} \\
\hline Yes & $1.7(110,1.28-2.12)$ & $1.5(34,1.02-2.07)$ \\
\hline No & $98.3(5737,97.88-98.72)$ & $98.6(1877,97.93-98.98)$ \\
\hline
\end{tabular}

$S D$ standard deviation, $C I$ confidence interval, $L O D$ limit of detection, $F E V 1$ forced expiratory volume in $1 \mathrm{~s}, F V C$ forced vital capacity

Of the 30,442 respondents in the NHANES 2007-2012 cross-sections, a total of $61.2 \%(n=18,619)$ were adults - with approximately a third $(n=5585)$ of the participants subsampled for phthalate metabolite levels (Table 3). Although adults with detectable phthalate metabolite values were slightly younger when compared with all adults, there was no difference in the weighted proportions of the subjects belonging to any race or living below the poverty threshold [poverty-toincome ratio (PIR) $<1$ ).

Self-reported asthma was seen in nearly $6 \%$ of both groups. With the spirometry measure, the proportion of asthmatics was more than doubled. This is expected given the nature of the US healthcare system with many adults in the US without health insurance and thus with undiagnosed asthma (Baldacci et al. 2015).

All participants (children and adults) had detectable concentrations of both LMW and HMW phthalate metabolites (detection frequency $>60 \%$ ) (Tables 4 and 5). With regard to LMW phthalates, MEP had the highest mean concentrations for both children and adults. For HMW phthalates, MECPP showed the highest in both groups.

The crude and adjusted model of associations between the different phthalate metabolites and self-reported asthma in children are shown in Fig. $1 \mathrm{a}$ and b, respectively. Selfreported childhood asthma was positively associated with MEP (1.45; 1.10-1.92), MiBP (1.62; 1.12-2.32), MnBP $(1.46 ; 1.05-2.02)$ and MBzP $(1.50 ; 1.09-2.08)$ in the crude analysis; with only MBzP $(1.54 ; 1.05-2.27)$ reaching statistical significance after adjusting for confounding variables.

Stratification by child's sex revealed that only the association between MEP and current asthma was modified, with a significant positive relationship among boys $(2.00 ; 1.14$ 3.51), but not among girls (Fig. 2). Effect modification was not observed for MBzP, despite the significant relationship found in the overall model.

The crude and adjusted analyses of associations between different phthalate metabolites and self-reported asthma in adults are shown in Fig. 3 a and b, respectively. No phthalate 
Table 3 Demographic and asthma status for all adults and subsets sampled for phthalate concentrations, NHANES 2007-2012

Adults aged 18 to $<80$ years

\begin{tabular}{|c|c|c|}
\hline Characteristics & All participants $(n=18619)$ & $\begin{array}{l}\text { Participants sampled for phthalate } \\
\text { concentrations }(\mathrm{n}=5585)\end{array}$ \\
\hline Age at screening (years), weighted mean (SD, 95\% CI) & $46.1(17.3,45.33-46.82)$ & $44.2(16.1,43.36-45.00)$ \\
\hline \multicolumn{3}{|l|}{ Sex } \\
\hline Male, weighted \% $(n, 95 \% \mathrm{CI})$ & $48.3(9140,47.59-49.06)$ & $49.4(2804,47.95-50.94)$ \\
\hline Female, weighted $\%(n, 95 \% \mathrm{CI})$ & $51.7(9479,50.94-52.41)$ & $50.6(2781,43.37-52.05)$ \\
\hline \multicolumn{3}{|l|}{ Race/ethnicity, weighted \% ( $n, 95 \% \mathrm{CI})$} \\
\hline Non-Hispanic whites & $67.6(8044,63.20-71.62)$ & $67.1(2323,62.74-71.25)$ \\
\hline Non-Hispanic Blacks & $11.6(4050,9.60-13.84)$ & $11.9(1271,9.80-14.33)$ \\
\hline Mexican American Hispanic & $8.4(2913,6.48-10.75)$ & $8.3(893,6.36-10.78)$ \\
\hline Others & $12.5(3612,10.70-14.61)$ & $12.7(1098,10.81-14.81)$ \\
\hline Waist circumference $(\mathrm{cm})$, weighted mean $(\mathrm{SD}, 95 \% \mathrm{CI})$ & $97.9(16.2,97.27-98.43)$ & $97.8(16.7,97.05-98.60)$ \\
\hline \multicolumn{3}{|l|}{ Family income-to-poverty ratio (PIR), weighted $\%(n, 95 \% \mathrm{CI})$} \\
\hline Below poverty (PIR $<1$ ), & $16.1(4003,14.56-17.78)$ & $16.2(1233,14.20-18.50)$ \\
\hline At or above poverty (PIR $\geq 1)$ & $83.9(12834,82.15-85.44)$ & $83.8(3837,81.50-85.80)$ \\
\hline Urinary creatinine $(\mathrm{mg} / \mathrm{dL})$, weighted mean $(\mathrm{SD}, 95 \% \mathrm{CI})$ & $120.8(77.9,117.84-123.81)$ & $121.4(78.7,118.28-124.49)$ \\
\hline \multicolumn{3}{|l|}{ Cotinine levels $(\mathrm{ng} / \mathrm{mL})$, weighted $\%(n, 95 \% \mathrm{CI})$} \\
\hline$<\operatorname{LOD}(<0.015)$ & $24.9(3724,23.28-26.69)$ & $25.1(1130,22.90-27.35)$ \\
\hline Low $(\geq 0.015$ to $<10)$ & $50.0(8844,48.47-51.50)$ & $49.2(2705,46.83-51.49)$ \\
\hline $\operatorname{High}(\geq 10)$ & $25.1(4216,23.58-26.60)$ & $25.8(1379,23.60-28.10)$ \\
\hline \multicolumn{3}{|c|}{ Current asthma based on self-reported questionnaire, weighted $\%(n, 95 \% \mathrm{CI})$} \\
\hline Yes & $5.9(1123,5.29-6.75)$ & $5.7(349,4.93-6.47)$ \\
\hline No & $94.0(17,463,93.24-94.71)$ & $94.3(5227,93.53-95.07)$ \\
\hline \multicolumn{3}{|c|}{ Current asthma based on spirometry $\mathrm{FEV}_{1} / \mathrm{FVC}$ cut-off, weighted \% (n, 95\% CI) } \\
\hline Yes & $13.4(1818,12.42-14.52)$ & $13.6(610,12.19-15.05)$ \\
\hline No & $86.6(12,353,85.48-87.58)$ & $86.4(4966,84.95-87.81)$ \\
\hline
\end{tabular}

$S D$ standard deviation, $C I$ confidence interval, $L O D$ limit of detection, $n$ number of observation, $F E V_{l}$ forced expiratory volume in $1 \mathrm{~s}, F V C$ forced vital capacity

metabolite showed a clear significant association with self-reported asthma in either the crude or the adjusted models. Effect modification by adult sex was not observed between any phthalate metabolites and selfreported asthma (Fig. 4).

Association of urinary phthalate metabolites, and current asthma in adults were re-analysed using spirometry data, with the results presented in Fig. 5 a and b. MiBP was inversely associated with asthma in adults in the unadjusted model $(0.73 ; 0.59-0.89)$, but the association did not reach statistical significance after adjusting for confounders. No other phthalate metabolites showed a significant relationship in either the crude nor the adjusted analyses.

The association of current asthma with MEP, MCPP and MCNP were not apparent in the overall model until after stratification by sex (Fig. 6). Similar to the result observed in children, a positive significant relationship was found between MEP and current asthma among adult males $(1.32 ; 1.04-1.69)$ but not for females $(1.03 ; 0.75-1.44)$. In contrast, MCPP and
MCNP were negatively associated with current asthma in adult females alone.

Sensitivity analyses examining the exposure-response associations demonstrated increases or decreases in the odds of current asthma with increasing exposure category (Additional file 1: Tables S2, S3 and S4). Overall, the results were consistent with the primary analysis in both children and adults. There was a significant positive association between MBzP exposure and self-reported asthma in children for the highest tertile relative to the lowest tertile $(1.99 ; 1.08-3.68)$, but not with any other phthalate metabolites. For male children, exposure to the highest tertile of MEP was significantly associated with over a 2-fold increased odds of self-reported asthma compared to the lowest tertile of MEP $(2.38 ; 1.107-$ 5.29). Similarly, adult males in the middle $(1.64 ; 1.01-2.68)$ and highest tertiles $(1.66 ; 1.07-2.2 .59)$ had an elevated odds of asthma compared to those in the lowest tertiles. With the exception of MEP, no other phthalate metabolites showed a positive association with current asthma in males. 
Table 4 Distribution of urinary phthalate concentrations for children (aged 6 to $<18$ years), NHANES 2007-2012

Percentile

\begin{tabular}{|c|c|c|c|c|c|c|c|c|c|c|c|}
\hline $\begin{array}{l}\text { Metabolite } \\
(\mathrm{ng} / \mathrm{mL})\end{array}$ & $\begin{array}{l}\text { Sample } \\
\text { size, } N\end{array}$ & $\begin{array}{l}\mathrm{LOD}_{\text {max }} \\
(\mathrm{ng} / \mathrm{mL})\end{array}$ & $\geq \mathrm{LOD}_{\max }(\%)^{\mathrm{a}}$ & $\begin{array}{l}\text { Weighted geometric } \\
\text { mean }(95 \% \mathrm{CI})\end{array}$ & Min & 5 th & 25 th & 50th & 75th & 95th & $\operatorname{Max}$ \\
\hline \multicolumn{12}{|c|}{ LMW phthalate } \\
\hline MEP & 2106 & 0.6 & 99.9 & $45.2(39.85-50.45)$ & $<\mathrm{LOD}_{\max }$ & 6.9 & 22.8 & 49.5 & 129.1 & 588.9 & 7633.2 \\
\hline MiBP & 2106 & 0.3 & 99.6 & $9.7(9.05-10.37)$ & $<\mathrm{LOD}_{\max }$ & 1.5 & 5.4 & 11.5 & 22.2 & 56.2 & 1163.3 \\
\hline $\mathrm{MnBP}$ & 2106 & 0.6 & 98.4 & $18.2(16.56-19.89)$ & $<\mathrm{LOD}_{\max }$ & 2.3 & 10.4 & 22.2 & 44.4 & 118.3 & 101013 \\
\hline \multicolumn{12}{|c|}{ HMW phthalate } \\
\hline $\mathrm{MBzP}$ & 2106 & 0.3 & 99.4 & $10.6(9.55-11.67)$ & $<\mathrm{LOD}_{\max }$ & 1.2 & 5.0 & 12.3 & 27.3 & 86.1 & 617.18 \\
\hline MCNP & 2106 & 0.5 & 96.3 & $3.0(2.72-3.19)$ & $<\mathrm{LOD}_{\max }$ & 0.5 & 1.7 & 3.1 & 5.5 & 14.6 & 334 \\
\hline MCPP & 2106 & 0.2 & 98.5 & $4.0(3.56-4.39)$ & $<\mathrm{LOD}_{\max }$ & 0.6 & 1.9 & 3.8 & 8.0 & 24.9 & 1425.8 \\
\hline$\Sigma \mathrm{DEHP}^{\mathrm{b}}$ & 2106 & - & - & $0.2(0.17-0.21)$ & 0.004 & 0.03 & 0.10 & 0.20 & 0.40 & 1.43 & 15.57 \\
\hline MEHP & 2106 & 1.1 & 66.7 & $2.1(1.96-2.23)$ & $<\mathrm{LOD}_{\max }$ & $<\mathrm{LOD}_{\max }$ & $<\mathrm{LOD}_{\max }$ & 1.9 & 4.2 & 15.3 & 204.7 \\
\hline MEHHP & 2106 & 0.7 & 99.4 & $16.1(14.58-17.65)$ & $<\mathrm{LOD}_{\max }$ & 2.2 & 7.8 & 17.2 & 36.5 & 133.3 & 1672 \\
\hline MECPP & 2106 & 0.5 & 100 & $27.1(24.67-29.56)$ & $<\mathrm{LOD}_{\max }$ & 5.0 & 14.6 & 28.4 & 56.4 & 194.1 & 1871 \\
\hline MEOHP & 2106 & 0.6 & 99.1 & $10.2(9.30-11.17)$ & $<\mathrm{LOD}_{\max }$ & 1.5 & 5.1 & 11.2 & 22.8 & 76.8 & 1175.1 \\
\hline
\end{tabular}

Results were, however, less consistent for adult females, with no significant relationship found using spirometry data as opposed to the inverse association found between MCNP and MCPP metabolites and current asthma in the primary analysis.

\section{Discussion}

In this study, we observed no clear relationship between phthalate exposure and asthma, apart from one significant

Table 5 Distribution of urinary phthalate concentrations for adults (aged 18 to $<80$ years), NHANES 2007-2012

Percentile

\begin{tabular}{|c|c|c|c|c|c|c|c|c|c|c|c|}
\hline $\begin{array}{l}\text { Metabolite } \\
(\mathrm{ng} / \mathrm{mL})\end{array}$ & $\begin{array}{l}\text { Sample } \\
\text { size, } N\end{array}$ & $\begin{array}{l}\mathrm{LOD}_{\text {max }} \\
(\mathrm{ng} / \mathrm{mL})\end{array}$ & $\geq \mathrm{LOD}_{\max }(\%)^{\mathrm{a}}$ & $\begin{array}{l}\text { Weighted geometric } \\
\text { mean }(95 \% \mathrm{CI})\end{array}$ & Min & 5 th & 25 th & 50 th & 75 th & 95th & Max \\
\hline \multicolumn{12}{|c|}{ LMW phthalate } \\
\hline MEP & 5417 & 0.6 & 99.9 & $63.6(58.95-68.35)$ & $<\mathrm{LOD}_{\max }$ & 6.8 & 26.1 & 72.1 & 224.3 & 1285 & 31,660 \\
\hline MiBP & 5417 & 0.3 & 98.7 & $6.5(6.12-6.90)$ & $<\mathrm{LOD}_{\max }$ & 0.9 & 3.8 & 8.1 & 15.5 & 40.0 & 627 \\
\hline $\mathrm{MnBP}$ & 5417 & 0.6 & 97.2 & $11.9(10.96-12.79)$ & $<\mathrm{LOD}_{\max }$ & 1.3 & 6.8 & 15.0 & 30.8 & 84.8 & 25,863 \\
\hline \multicolumn{12}{|c|}{ HMW phthalate } \\
\hline $\mathrm{MBzP}$ & 5417 & 0.3 & 97.8 & $5.3(4.93-5.63)$ & $<\mathrm{LOD}_{\max }$ & 0.6 & 2.5 & 5.9 & 13.4 & 42.3 & 450.2 \\
\hline MCNP & 5417 & 0.5 & 92.7 & $2.6(2.42-2.72)$ & $<\mathrm{LOD}_{\max }$ & $<$ LOD & 1.2 & 2.4 & 4.8 & 16.2 & 730.25 \\
\hline MCPP & 5417 & 0.2 & 97.4 & $2.8(2.54-2.99)$ & $<\mathrm{LOD}_{\max }$ & 0.3 & 1.2 & 2.6 & 5.6 & 22.4 & 2597.3 \\
\hline$\Sigma \mathrm{DEHP}^{\mathrm{b}}$ & 5417 & - & - & $0.1(0.13-0.15)$ & 0.003 & 0.02 & 0.07 & 0.14 & 0.30 & 1.1 & 106.72 \\
\hline MEHP & 5417 & 1.1 & 62.8 & $2.1(1.92-2.20)$ & $<\mathrm{LOD}_{\max }$ & $<\mathrm{LOD}_{\max }$ & $<\mathrm{LOD}_{\max }$ & 1.7 & 4.0 & 16.9 & 1252.7 \\
\hline MEHHP & 5417 & 0.7 & 98.5 & $12.5(11.52-13.52)$ & $<\mathrm{LOD}_{\max }$ & 1.6 & 5.9 & 12.8 & 27.3 & 116.3 & 9326.1 \\
\hline МЕCPР & 5417 & 0.5 & 99.8 & 19.5 (17.99-20.92) & $<\mathrm{LOD}_{\max }$ & 3.1 & 9.5 & 19.8 & 40.7 & 148.1 & 15828 \\
\hline MEOHP & 5417 & 0.6 & 97.8 & $7.5(6.90-8.07)$ & $<\mathrm{LOD}_{\max }$ & 1.0 & 3.6 & 7.7 & 16.1 & 62.1 & 6079.9 \\
\hline
\end{tabular}

$N$ number of participants/urinary samples, $L O D$ limit of detection, Min minimum, 5 th 5 th percentile, 25 th 25 th percentile, 50 th 50 th percentile, 75 th 75 th percentile, 95th 95th percentile, Max maximum, $L M W$ low molecular weight, $M M P$ mono-n-methyl phthalate, $M E P$ mono-ethyl phthalate, $M i B P$ monoisobutyl phthalate, $M n B P$ mono-n-butyl phthalate, $H W M$ high molecular weight, $M i N P$ mono-isononyl phthalate, $M B z P$ mono-benzyl phthalate, $M C N P$ mono (carboxylnonyl) phthalate, $M C P P$ mono-(3-carboxylpropyl) phthalate, $D E H P$ di(2-ethylhexyl) phthalate, $M E H P$ mono-(2-ethylhexyl) phthalate, MEHHP mono-(2-ethyl-5-hydroxylhexyl) phthalate, MECPP mono-(2-ethyl-5-carboxylpentyl) phthalate, MEOHP mono-(2-ethyl-5-oxohexyl) phthalate

${ }^{a}$ Percentage of phthalate metabolite concentrations at or above the maximum limit of detection $\left(<\mathrm{LOD}_{\max }\right)$. All concentrations below the $\mathrm{LOD}$ max $(<$ $\left.L O D_{\text {max }}\right)$ were substituted with a value of $\mathrm{LOD}_{\max }$ divided by square root of two $(\sqrt{2})$

${ }^{\mathrm{b}} \Sigma$ DEHP: molar sum of DEHP metabolites (MEHP, MEHHP, MECPP and MEOHP) expressed in $\mu \mathrm{mol} / \mathrm{L}$. 


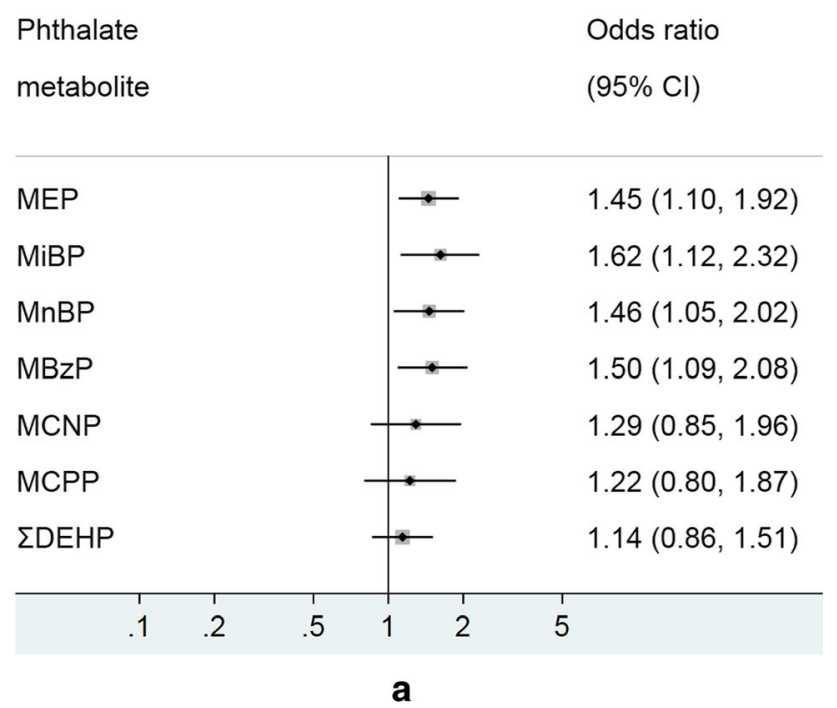

Phthalate

Odds ratio

metabolite

$(95 \% \mathrm{Cl})$

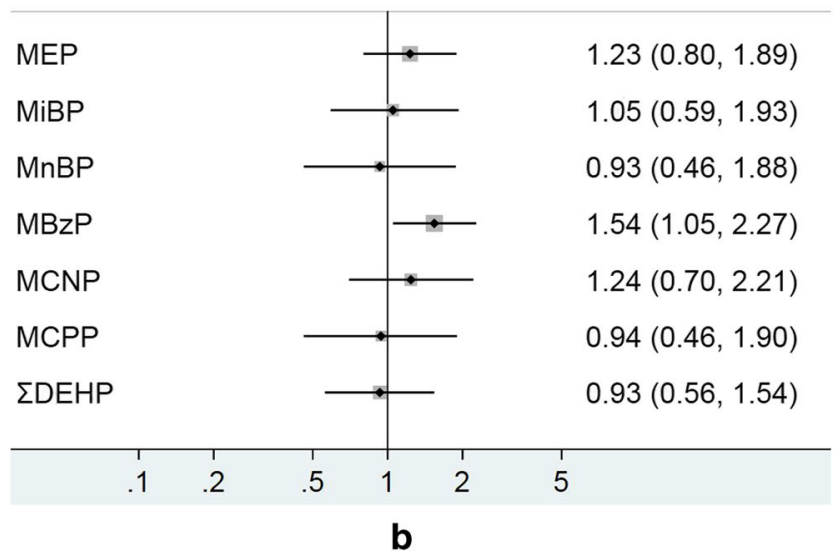

Fig. 1 a Model 1 (crude) - associations of urinary phthalate metabolites with self-reported asthma in children, NHANES 2007-2012. Logistic regression modeling was used to access the effect of individual phthalate metabolites on asthma prevalence, with an odds ratio (OR) presented for 1 $\log _{10}$ unit change in urinary phthalate concentration. b Model 2 (adjusted) - associations of urinary phthalate metabolites with self-reported asthma in children, NHANES 2007-2012. Logistic regression modeling was used to access the effect of individual phthalate metabolites on asthma prevalence, with an OR presented for $1 \log _{10}$ unit change in urinary phthalate concentration. MEP mono-ethyl phthalate, MiBP monoisobutyl phthalate, MnBP mono-n-butyl phthalate, MBzP mono-benzyl phthalate, MCNP mono-(carboxynonyl) phthalate, MCPP mono-(3carboxylpropyl) phthalate, $\Sigma$ DEHP molar sum of DEHP metabolites (MEHP, MEHHP, MECPP and MEOHP). All models were adjusted for age, sex, ethnicity/race, waist circumference, cotinine, poverty and urinary creatinine

association between $\mathrm{MBzP}$ and self-reported asthma in children. Stratification by sex revealed that both boys and adult males are not at increased odds of current asthma following exposure to the majority of phthalate metabolites apart from the MEP metabolite. We found associations of MCNP and
Phthalate

Odds ratio

(sex)

$(95 \% \mathrm{Cl})$

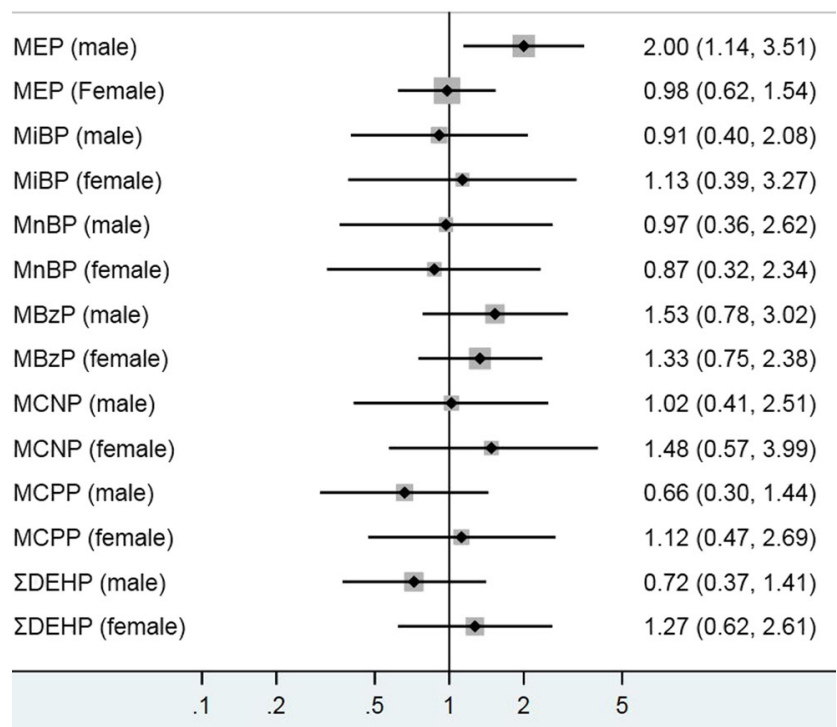

Fig. 2 Associations between urinary phthalate metabolites and asthma (self-reported) in children stratified by sex. Logistic regression modeling was used to access the effect of individual phthalate metabolites on asthma prevalence, with odds ratio (OR) presented for $1 \log _{10}$ unit change in urinary phthalate concentration. MEP mono-ethyl phthalate, MiBP mono-isobutyl phthalate, MnBP mono-n-butyl phthalate, MBzP monobenzyl phthalate, MCNP mono-(carboxynonyl) phthalate, MCPP mono(3-carboxylpropyl) phthalate, $\mathrm{DDEHP}$ molar sum of DEHP metabolites (MEHP, MEHHP, MECPP and MEOHP). All models were adjusted for age, race/ethnicity, waist circumference, poverty, urinary creatinine and cotinine

MCPP concentrations with reduced odds of asthma (defined using $\mathrm{FEV}_{1} / \mathrm{FVC} 70 \%$ cut off) among adult females. MiBP, $\mathrm{MnBP}$ and $\Sigma \mathrm{DEHP}$ were not significantly associated with either self-reported or objectively defined asthma (spirometry measure) in both children and adults.

Whyatt et al. (2014) examined the relationship between the diagnosis of asthma in children (aged 5-11 years, $n=300$ ) and prenatal exposures BBzP, di-n-butyl phthalate (DnBP), DEHP and di-ethyl phthalate (DEP) using a longitudinal birth cohort of 727 women enrolled between 1998 and 2006. They found that maternal prenatal MBzP and MnBP concentrationsmetabolites of HMW BBzP and DnBP, respectively-were significantly associated with the diagnosis of current asthma and with a history of asthma-like symptoms (Whyatt et al. 2014). The present study found a significant association between MBzP and self-reported asthma in children, but no relationship was found for $\mathrm{MnBP}$.

A positive correlation was found between an HMW metabolite, DEHP exposure and asthma in settled dust (Gascon et al. 2015), but not with MBzP (Bornehag et al. 2004; Kolarik et al. 2008). A cross-sectional study of 623 Norwegian children aged 10 years old reported a significant relationship with the highest quartiles of MCNP and mono-(carboxyloctyl) 


\section{Phthalate}

metabolite

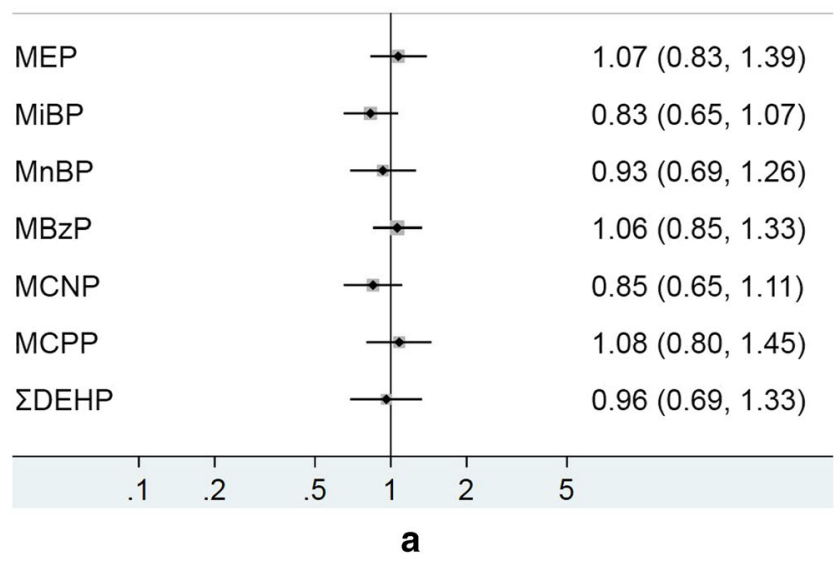

Phthalate

Odds ratio

metabolite

$(95 \% \mathrm{Cl})$

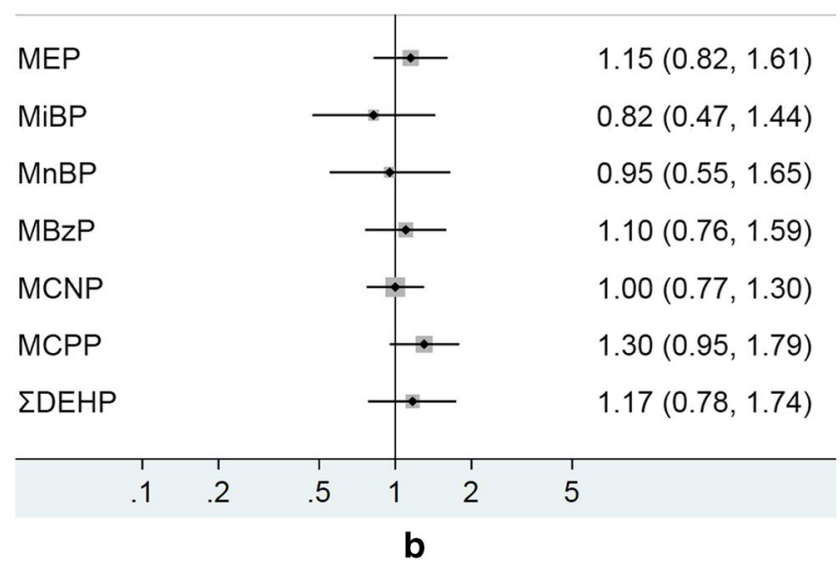

Fig. 3 a Model 1 (crude) - associations of urinary phthalate metabolites with self-reported asthma in adults, NHANES 2007-2012. Logistic regression modeling was used to access the effect of individual phthalate metabolites on asthma prevalence, with odds ratio (OR) presented for 1 $\log _{10}$ unit change in urinary phthalate concentration. b Model 2 (adjusted) - associations of urinary phthalate metabolites with self-reported asthma in children, NHANES 2007-2012. Logistic regression modeling was used to access the effect of individual phthalate metabolites on asthma prevalence, with odds ratio (OR) presented for $1 \log _{10}$ unit change in urinary phthalate concentration. MEP mono-ethyl phthalate, MiBP mono-isobutyl phthalate, MnBP mono-n-butyl phthalate, MBzP monobenzyl phthalate, MCNP mono-(carboxynonyl) phthalate, MCPP mono(3-carboxylpropyl) phthalate, $\mathrm{DEEHP}$ molar sum of DEHP metabolites (MEHP, MEHHP, MECPP and MEOHP). All models were adjusted for age, sex, ethnicity/race, waist circumference, cotinine, poverty and urinary creatinine

phthalate (MCOP) (Bertelsen et al. 2013). However, we did not find a positive association of childhood asthma with DEHP or MCNP in either the crude or the adjusted analyses. This disparity may be attributed in part to the matrix examined, dust (Gascon et al. 2015; Bornehag et al. 2004; Kolarik et al. 2008) versus urine (Bertelsen et al. 2013). Another possible

\section{Phthalate}

Odds ratio

(sex)

$(95 \% \mathrm{Cl})$

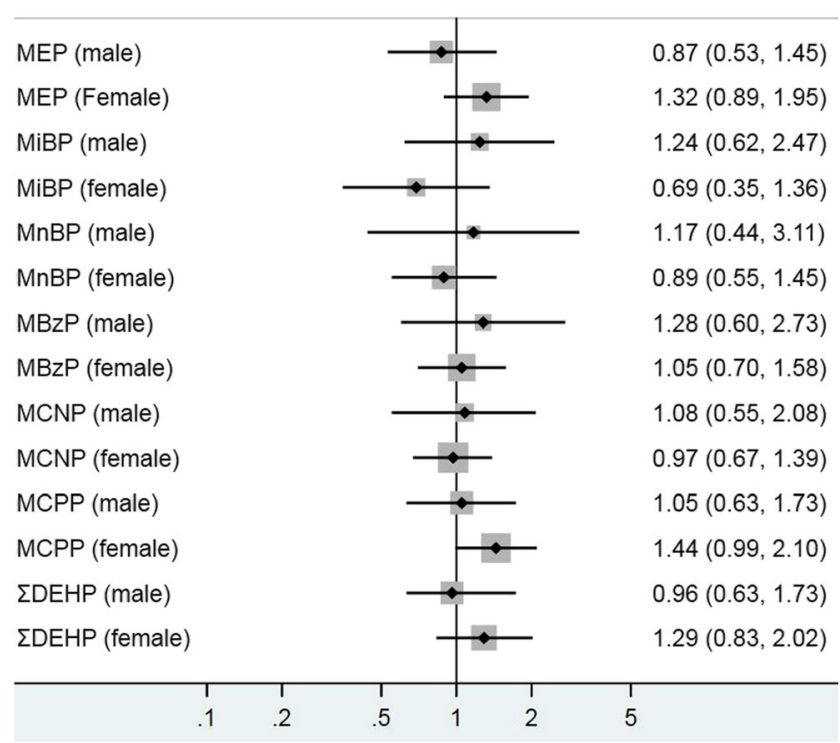

Fig. 4 Associations between urinary phthalate metabolites and asthma (self-reported) in adults stratified by sex. Logistic regression modeling was used to access the effect of individual phthalate metabolites on asthma prevalence, with odds ratio (OR) presented for $1 \log _{10}$ unit change in urinary phthalate concentration. MEP mono-ethyl phthalate, MiBP mono-isobutyl phthalate, MnBP mono-n-butyl phthalate, MBzP monobenzyl phthalate, MCNP mono-(carboxynonyl) phthalate, MCPP mono(3-carboxylpropyl) phthalate, DDEHP molar sum of DEHP metabolites (MEHP, MEHHP, MECPP and MEOHP). All models were adjusted for age, race/ethnicity, waist circumference, urinary creatinine and cotinine

explanation might be the differences in specimen collection (i.e. the use of first-morning void (Bertelsen et al. 2013) as opposed to spot urine in the present study), as these may affect the concentrations of phthalate metabolites measured.

$\mathrm{MBzP}$ is a primary metabolite of $\mathrm{BBz}$, an HMW phthalate used in the manufacturing of toys, PVC materials, child care articles and personal care products, and for pharmaceutical coatings (Benjamin et al. 2017; Braun et al. 2013). While exposure to some phthalate compounds, particularly among asthmatics, may be via pharmaceuticals, Hoppin et al. (2013) suggested that the presence of MBzP in urine is unlikely to be as a result of the use of asthma medication since $\mathrm{BBzP}$ is not approved for pharmaceutical coatings. Compared with nonasthmatics, Hsu et al. (2012) (Hsu et al. 2012) demonstrated that asthmatic children had significantly higher levels of BBzP determined in settled dust, even after controlling for other indoor air pollutants. They proposed that the inhalation of BBzP may be an important pathway to the development or exacerbation of asthma in children in Taiwan (Hsu et al. 2012).

In a study using the NHANES data, Hoppin et al. (2013) showed that HMW phthalate metabolites, particularly MBzP, were positively associated with current asthma, current 


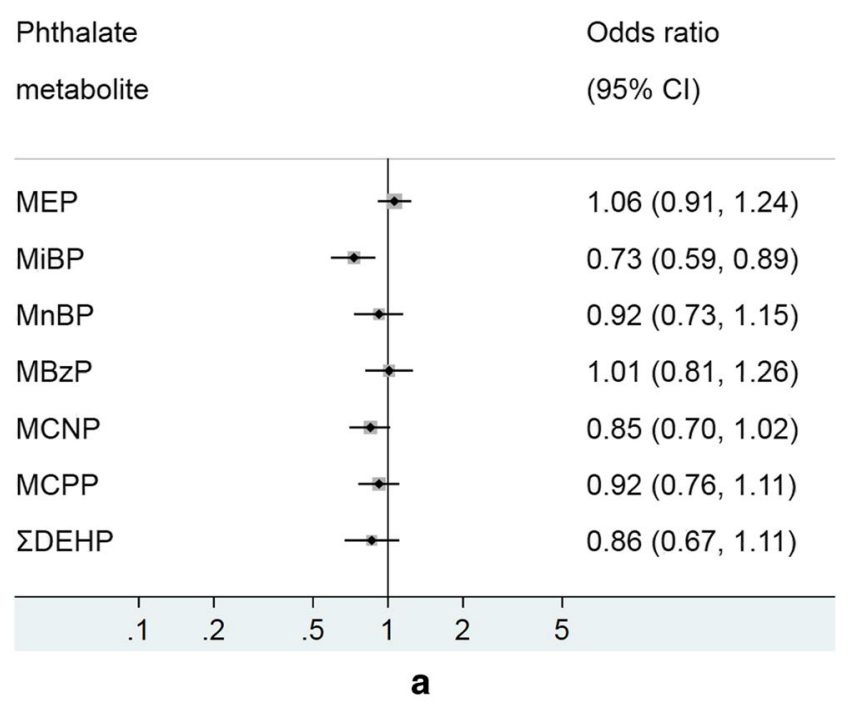

Phthalate Odds ratio

metabolite

$(95 \% \mathrm{Cl})$

\begin{tabular}{|c|c|c|c|c|}
\hline MEP & & & $\rightarrow$ & $1.15(0.93,1.43)$ \\
\hline MiBP & & & & $0.78(0.54,1.11)$ \\
\hline MnBP & & & & $0.93(0.66,1.32)$ \\
\hline MBzP & & & $\rightarrow$ & $1.24(0.92,1.68)$ \\
\hline MCNP & & & & $0.84(0.65,1.08)$ \\
\hline MCPP & & & & $0.86(0.66,1.13)$ \\
\hline$\Sigma$ DEHP & & & - & $0.93(0.66,1.30)$ \\
\hline .1 & .2 & .5 & 2 & 5 \\
\hline
\end{tabular}

Fig. 5 a Model 1 (crude) - associations of urinary phthalate metabolites with current asthma (spirometry measure) in adults, NHANES 20072012. Logistic regression modeling was used to access the effect of individual phthalate metabolites on asthma prevalence, with odds ratio (OR) presented for $1 \log _{10}$ unit change in urinary phthalate concentration. b Model 2 (adjusted) - associations of urinary phthalate metabolites with current asthma (spirometry measure) in adults, NHANES 2007-2012. Logistic regression modeling was used to access the effect of individual phthalate metabolites on asthma prevalence, with odds ratio (OR) presented for $1 \log _{10}$ unit change in urinary phthalate concentration. MEP mono-ethyl phthalate, MiBP mono-isobutyl phthalate, MnBP mono-nbutyl phthalate, MBzP mono-benzyl phthalate, MCNP mono(carboxynonyl) phthalate, MCPP mono-(3-carboxylpropyl) phthalate, DEHP molar sum of DEHP metabolites (MEHP, MEHHP, MECPP and MEOHP). All models were adjusted for age, sex, ethnicity/race, waist circumference, cotinine, poverty, and urinary creatinine

wheeze, current hay fever, and current rhinitis in adults (aged 18 years and older, $n=1596$ ), but not in children (aged 6 17 years, $n=779$ ). This disparity with our analysis may be attributed to the asthma definition and/or the measurement method used. Hoppin et al. (2013) separated the definition of current asthma and wheeze in their analysis, whereas the

\section{Phthalate}

Odds ratio

(sex)

$(95 \% \mathrm{Cl})$

Fig. 6 Associations between urinary phthalate metabolites and current asthma (spirometry measure in adults stratified by sex. Logistic regression modeling was used to access the effect of individual phthalate metabolites on asthma prevalence, with odds ratio (OR) presented for $1 \log _{10}$ unit change in urinary phthalate concentration. MEP mono-ethyl phthalate, MiBP mono-isobutyl phthalate, MnBP mono-nbutyl phthalate, MBzP mono-benzyl phthalate, MCNP mono(carboxynonyl) phthalate, MCPP mono-(3-carboxylpropyl) phthalate, $\Sigma$ DEHP molar sum of DEHP metabolites (MEHP, MEHHP, MECPP and MEOHP). All models were adjusted for age, race/ethnicity, waist circumference, urinary creatinine and cotinine

present study combined these self-reported measures. It is also possible that our findings for children may have occurred by chance alone since no other phthalate analysed showed a significant relationship in the adjusted models.

We did observe that the weighted geometric mean concentration of MBzP in children was two-fold the level seen in adults (Tables 4 and 5). This suggests that children are more exposed to MBzP than adults and may be at increased odds of asthma following this exposure. It is important to note that our findings for children should, however, be interpreted with caution. While one (MBzP metabolite) out of ten metabolites analysed was positively associated with asthma, this does not suggest any strong relationship between phthalates and asthma. For adults, using both self-reported and spirometry data of the present study, there were no associations between any phthalate metabolite and current asthma.

With respect to effect modification by sex, Ku et al. (2015) reported that exposure to MEP metabolite was significantly associated with an increased odds of asthma among boys, but not among girls; and this was reflected in our study. Analysis of 240 adult participants (140 females, 100 males; 20 to 60 years) of NHANES III revealed that MEP levels in urine were associated with a reduction in pulmonary function 
measures (FEV1, FVC) in adult males alone (Hoppin et al. 2004). A similar study of 3147 participants (aged between 6 and 49 years) found significant associations between MEP, MnBP, MCPP and 5 DEHP exposure, and a reduction in $\mathrm{FEV}_{1}$ or FVC in men (Cakmak et al. 2014). Although an inverse association was found between MCPP and MCNP metabolites and current asthma in adult females, our result for MEP was consistent with previous studies for both boys and adult males.

MEP is a primary metabolite of DEP, an LMW phthalate used in varieties of consumer products including fragrances and personal care products. Sex differences in MEP concentrations have been explained based on the use of these products, with evidence of higher MEP levels in females than in males (Saravanabhavan et al. 2014). However, our finding suggests that higher exposure to DEP may not explain the observed association among males. The sex-specific relationship may be attributed to either the endocrine disruptive ability of DEP in relation to sex differences in asthma prevalence (Buckley et al. 2018), or the hormonal influence of the chemical on the functioning of lungs and the immune systems. It is also plausible that the interactions between gene and environmental exposure to DEP may have resulted in sex-specific differences and the observed male susceptibility to asthma prevalence.

Although the pathways through which phthalates induce asthma in humans remain unclear (Whyatt et al. 2014), animal studies have provided stronger evidence of their deleterious effects. For example, the metabolites of HMW phthalates, especially MBzP and MEHP, were shown to bind with and activate the nuclear peroxisome proliferator-activated receptors (PPAR-alpha and PPAR-gamma), which play a significant role in certain physiological processes including airway remodeling and inflammation in rodents (Hurst and Waxman 2003). More recently, in vivo studies have demonstrated that DEHP induces Th2 and Th17 immune responses and airway inflammation in mice (Alfardan et al. 2018), and thymic stromal lymphopoietin (TSLP), Th2 immune response and interleukin-7 receptor in rats (Wang et al. 2018); all of which exacerbates asthma.

Some limitations of the study include the cross-sectional design of NHANES making it difficult to establish causality in the associations between phthalate exposures and asthma in children and adults. Phthalate measurements are prone to exposure misclassification via the use of a single spot urine sample per subject, which may not take into account the variation of within-person over time. Nevertheless, although phthalate metabolites have biological half-lives of less than a day (Jepsen et al. 2004; Ferguson et al. 2011), research has shown that, despite this temporal variability, the measurement of phthalate concentrations via a single spot urine sample may be a representative of long-term exposures (Teitelbaum et al. 2008). We were unable to repeat the analysis for children using spirometry data. This is because $\mathrm{FEV}_{1} / \mathrm{FVC}$ was considered a poor diagnostic test for childhood asthma due to a lack of accuracy and precision (Murray et al. 2016) and the limited number of children classified as asthmatics $(<2 \%)$ compared to non-asthmatics (>98\%) (Table 2). This prevented us from investigating if the observed association between MBzP metabolites and self-reported asthma in children were overestimated or due to chance. Finally, some children and adults with asthma, particularly of lower socioeconomic status (SES), may not have received a diagnosis of asthma due to lack of healthcare; and thus, are unaware of their current asthma status.

However, the strengths of the study include using three NHANES waves based on a representative sample of the US population that is diverse in terms of geographical distribution, ethnic groups, age, and income. Current asthma was defined using both subjective (self-reported) and objective (spirometry) measures in adults. Both our primary and sensitivity analyses were robust in statistical modeling approaches and may be generalised to the US population.

\section{Conclusions}

Urinary concentrations of phthalate metabolites were not significantly associated with current asthma in children and adults, apart from a single metabolite. Stratification by sex revealed that boys and adult males were at increased odds of asthma following exposure to only MEP; adult females were at decreased odds of asthma following exposure to MCNP and MCPP. Based on our findings, the potential adverse effect of phthalate exposure on asthma pathogenesis and/or exacerbations remains controversial, highlighting the need for a more comprehensive study on phthalate exposure and the occurrence of asthma; ideally, integrating a well-designed longitudinal follow-up analysis would be more informative.

Availability of data and materials The datasets used for this analysis are publicly available on the NHANES website: https://wwwn.cdc.gov/nchs/ nhanes/search/datapage.aspx?Component=Demographics

Authors' contributions C.C.O. and N.J.O. conceived the original study; C.C.O obtained the data, cleaned it, and conducted the main analysis under the direction and supervision of N.J.O.; C.C.O. wrote the paper; and N.J.O., T.J.T. and L.E.F. contributed to the writing, advice and amendments of the paper.

Funding C.C.O. conducted this study as part of a Master's Degree and received funding from the Commonwealth Scholarship Commission in the UK and the University of Exeter.

Data Availability The datasets used for this analysis are publicly available on the NHANES website: https://wwwn.cdc.gov/nchs/nhanes/search/ datapage.aspx?Component=Demographics 


\section{Compliance with ethical standards}

Ethics approval and consent to participate Ethics for the collection of the original NHANES data and consent for participation were addressed by the NHANES Ethics Review Board (ERB): see https://www.cdc.gov/ nchs/nhanes/irba98.htm Ethical approval for the secondary analysis was obtained from the University of Exeter Medical School's Ethics Committee.

\section{Consent for publication Not applicable.}

Competing interests The authors declare that they have no competing interests.

\begin{abstract}
Abbreviations ATS, American Thoracic Society; $B B z P$, benzylbutyl phthalate; $B M I$, body mass index; $C D C$, Centers for Disease Control and Prevention; $C I$, confidence interval; $\mathrm{cm}$, centimetre; $D A L Y s$, disability-adjusted life years; $D E H P$, di-(2-ethylhexyl) phthalate; $D E P$, di-ethyl phthalate; $E D$, emergency department; $E R S$, European Respiratory Society; $F E V_{l}$, forced expiratory volume in $1 \mathrm{~s} ; F V C$, forced vital capacity; $H M W$, high molecular weight; ISAAC, The International Study of Asthma and Allergies in Childhood; $L M W$, low molecular weight; $L O D$, limit of detection; $L O D_{\max }$, maximum limit of detection; $M B z P$, mono-benzyl phthalate; $M C N P$, mono-(carboxylnonyl) phthalate; $M C O P$, mono-(carboxyloctyl) phthalate; $M C P P$, mono-(3carboxylpropyl) phthalate; $M E C P P$, mono-(2-ethyl-5-oxohexyl) phthalate; $M E H H P$, mono-(2-ethyl-5-hydroxylhexyl) phthalate; $M E H P$, mono-(2-ethyl-5-hexyl) phthalate; $M E O H P$, mono-(2-ethyl-5-oxohexyl) phthalate; $M E P$, mono-ethyl phthalate; $M i B P$, mono-iso-butyl phthalate; $M n B P$, mono-n-butyl phthalate; NCHS, National Centre for Health Statistics; NHANES, National Health and Nutrition Examination Survey; NHS, National Health Service; OR, odds ratio; PIR, income to poverty ratio; PPARs, peroxisome proliferator-activated receptors; $P V C$, polyvinyl chloride; SES, socioeconomic status; TSLP, thymic stromal lymphopoietin; UK, United Kingdom; US, United States; YLLs, years of life lost
\end{abstract}

Open Access This article is distributed under the terms of the Creative Commons Attribution 4.0 International License (http:// creativecommons.org/licenses/by/4.0/), which permits unrestricted use, distribution, and reproduction in any medium, provided you give appropriate credit to the original author(s) and the source, provide a link to the Creative Commons license, and indicate if changes were made.

\section{References}

Abo-Zaid G, Sharpe RA, Fleming LE, Depledge M, Osborne NJ (2018) Association of infant eczema with childhood and adult asthma: analysis of data from the 1958 birth cohort study. Int J Environ Res Public Health 15(7):1415. https://doi.org/10.3390/ijerph15071415

Alfardan AS, Nadeem A, Ahmad SF, Al-Harbi NO, Al-Harbi MM, AlSharari SD (2018) Plasticizer, di (2-ethylhexyl) phthalate (DEHP) enhances cockroach allergen extract-driven airway inflammation by enhancing pulmonary Th2 as well as Th17 immune responses in mice. Environ Res 164:327-339

Almqvist C, Worm M, Leynaert B (2008) Impact of gender on asthma in childhood and adolescence: a GA2LEN review. Allergy 63(1):4757

Asher MI, Montefort S, Björkstén B, Lai CKW, Strachan DP, Weiland SK, Williams H (2006) Worldwide time trends in the prevalence of symptoms of asthma, allergic rhinoconjunctivitis, and eczema in childhood: ISAAC Phases One and Three repeat multicountry cross-sectional surveys. Lancet 368(9537):733-743

Bai PY, Wittert G, Taylor AW, Martin SA, Milne RW, Jenkins AJ, Januszewski AS, Shi Z (2017) The association between total phthalate concentration and non-communicable diseases and chronic inflammation in South Australian urban dwelling men. Environ Res 158:366-372

Baldacci S, Maio S, Cerrai S, Sarno G, Baïz N, Simoni M, AnnesiMaesano I, Viegi G (2015) Allergy and asthma: effects of the exposure to particulate matter and biological allergens. Respir Med 109(9): 1089-1104

Benjamin S, Masai E, Kamimura N, Takahashi K, Anderson RC, Faisal PA (2017) Phthalates impact human health: epidemiological evidences and plausible mechanism of action. J Hazard Mater 340: 360-383

Bertelsen RJ, Carlsen KCL, Calafat AM, Hoppin JA, Håland G, Mowinckel P, Carlsen KH, Løvik M (2013) Urinary biomarkers for phthalates associated with asthma in Norwegian children. Environ Health Perspect 121(2):251-256

Bjornson CL, Mitchell I (2000) Gender differences in asthma in childhood and adolescence. J Gender-Specif Med 3(8):57-61

Bølling AK, Holme JA, Bornehag CG, Nygaard UC, Bertelsen RJ, Nånberg E et al (2013) Pulmonary phthalate exposure and asthmais PPAR a plausible mechanistic link? EXCLI J 12:733

Bornehag C-G, Sundell J, Weschler CJ, Sigsgaard T, Lundgren B, Hasselgren M, Hägerhed-Engman L (2004) The association between asthma and allergic symptoms in children and phthalates in house dust: a nested case-control study. Environ Health Perspect 112(14):1393-1397

Braun JM, Sathyanarayana S, Hauser R (2013) Phthalate exposure and children's health. Curr Opin Pediatr 25(2):247-254

Buckley JP, Quirós-Alcalá L, Teitelbaum SL, Calafat AM, Wolff MS, Engel SM (2018) Associations of prenatal environmental phenol and phthalate biomarkers with respiratory and allergic diseases among children aged 6 and 7 years. Environ Int 115:79-88

Cakmak S, Dales RE, Hebbern C, Saravanabhavan G (2014) The association between urinary phthalates and lung function. J Occup Environ Med 56(4):376-381

Carlsen KCL, Roll S, Carlsen K-H, Mowinckel P, Wijga AH, Brunekreef $B$ et al (2012) Does pet ownership in infancy lead to asthma or allergy at school age? Pooled analysis of individual participant data from 11 European birth cohorts. PLoS One 7(8):e43214

Centers for Disease Control and Prevention (2008) Adult self-reported current asthma prevalence rate by sex and state or territory: BRFSS http://www.cdc.gov/asthma/brfss/08/current/tableC21.htm Accessed 2 July 2018

Centre for Disease Control and Prevention CDC (2017) Asthma. https:// www.cdc.gov/nchs/fastats/asthma.htm. Accessed 20 July 2018

Cerveri I, Corsico AG, Accordini S, Niniano R, Ansaldo E, Antó JM et al (2008) Underestimation of airflow obstruction among young adults using FEV1/FVC $<70 \%$ as a fixed cut-off: a longitudinal evaluation of clinical and functional outcomes. Thorax 63:1040-1045

De Marco R, Locatelli F, Sunyer J, Burney P (2000) Differences in incidence of reported asthma related to age in men and women: a retrospective analysis of the data of the European Respiratory Health Survey. Am J Respir Crit Care Med 162(1):68-74

Dong R, Zhao S, Zhang H, Chen J, Zhang M, Wang M, Wu M, Li S, Chen B (2017) Sex differences in the association of urinary concentrations of phthalates metabolites with self-reported diabetes and cardiovascular diseases in Shanghai adults. Int J Environ Res Public Health 14(6):598

Ferguson KK, Loch-Caruso R, Meeker JD (2011) Urinary phthalate metabolites in relation to biomarkers of inflammation and oxidative stress: NHANES 1999-2006. Environ Res 111(5):718-726

Gascon M, Casas M, Morales E, Valvi D, Ballesteros-Gómez A, Luque N et al (2015) Prenatal exposure to bisphenol a and phthalates and 
childhood respiratory tract infections and allergy. J Allergy Clin Immunol 35(2):370-378

Hoppin JA, Ulmer R, London SJ (2004) Phthalate exposure and pulmonary function. Environ Health Perspect 112(5):571-574

Hoppin JA, Jaramillo R, London SJ, Bertelsen RJ, Salo PM, Sandler DP, Zeldin DC (2013) Phthalate exposure and allergy in the US population: results from NHANES 2005-2006. Environ Health Perspect 121(10):1129-1134

Hsu NY, Lee CC, Wang JY, Li YC, Chang HW, Chen CY, Bornehag CG, Wu PC, Sundell J, Su HJ (2012) Predicted risk of childhood allergy, asthma, and reported symptoms using measured phthalate exposure in dust and urine. Indoor Air 22(3): 186-199

Hurst CH, Waxman DJ (2003) Activation of PPAR $\alpha$ and PPAR $\gamma$ by environmental phthalate monoesters. Toxicol Sci 74(2):297-308

James-Todd TM, Huang T, Seely EW, Saxena AR (2016) The association between phthalates and metabolic syndrome: the National Health and Nutrition Examination Survey 2001-2010. Environ Health 15(1):52

Janssen I, Katzmarzyk PT, Ross R (2004) Waist circumference and not body mass index explains obesity-related health risk. Am J Clin Nutr 79(3):379-384

Jepsen KF, Abildtrup A, Larsen ST (2004) Monophthalates promote IL-6 and IL-8 production in the human epithelial cell line A549. Toxicol in Vitro 18(3):265-269

Johnson CL, Paulose-Ram R, Ogden CL, Carroll MD, Kruszan-Moran D, Dohrmann SM et al (2013) National health and nutrition examination survey: analytic guidelines, 1999-2010. Vital Health Stat 166:1-24

Khalili R, Bartell SM, Hu X, Liu Y, Chang HH, Belanoff C et al (2018) Early-life exposure to PM 2.5 and risk of acute asthma clinical encounters among children in Massachusetts: a case-crossover analysis. Environmental. Health 17(1):20

Kolarik B, Naydenov K, Larsson M, Bornehag C-G, Sundell J (2008) The association between phthalates in dust and allergic diseases among Bulgarian children. Environ Health Perspect 116(1):98-103

$\mathrm{Ku} \mathrm{HY}$, Su PH, Wen HJ, Sun HL, Wang CJ, Chen HY, Jaakkola JJK, Wang SL, TMICS Group (2015) Prenatal and postnatal exposure to phthalate esters and asthma: a 9-year follow-up study of a taiwanese birth cohort. PLoS One 10(4):e0123309

Kuo P-L, Hsu Y-L, Huang M-S, Tsai M-J, Ko Y-C (2011) Ginger suppresses phthalate ester-induced airway remodeling. J Agric Food Chem 59(7):3429-3438

Laboratory procedure manual (2013) phthalates and phthalate alternative metabolites. https://wwwn.cdc.gov/nchs/data/nhanes/2013-2014/ labmethods/PHTHTE_H_MET_Phthalates.pdf. Accessed 5 August 2018

Li MC, Chen CH, Guo YL (2017) Phthalate esters and childhood asthma: a systematic review and congener-specific meta-analysis. Environ Pollut 229:655-660

Mazurek JM, Syamlal G (2018) Prevalence of asthma, asthma attacks, and emergency department visits for asthma among working adults-National Health Interview Survey, 2011-2016. Morb Mortal Wkly Rep 67(13):377-386

Murray CS, Foden P, Lowe LA, Durrington H, Custovic A, Simpson A (2016) P176 diagnosing asthma in children using spirometry: evidence from a birth cohort study. BMJ Publishing Group Ltd.

National Health and Nutrition Examination Survey (2014) Spirometrypre and post-bronchodilator. https://wwwn.cdc.gov/Nchs/Nhanes/ 2011-2012/SPX_G.htm. Accessed 15 August 2018

National Health and Nutrition Examination Survey (NHANES) (2008) Respiratory Health spirometry procedures manual. https://www.cdc. gov/nchs/data/nhanes/nhanes_07_08/spirometry.pdf. Accessed 15 August 2018
National Health and Nutrition Examination Survey (NHANES) (2017) Information for participants. https://www.cdc.gov/nchs/nhanes/ biospecimens/participants.htm. Accessed 15 August 2018

Nishioka J, Iwahara C, Kawasaki M, Yoshizaki F, Nakayama H, Takamori K, Ogawa H, Iwabuchi K (2012) Di-(2-ethylhexyl) phthalate induces production of inflammatory molecules in human macrophages. Inflamm Res 61(1):69-78

Nurmagambetov T, Kuwahara R, Garbe P (2018) The economic burden of asthma in the United States, 2008-2013. Annals of the American Thoracic Society 15(3):348-356

Osborne NJ, Alcock I, Wheeler BW, Hajat S, Sarran C, Clewlow Y, McInnes RN, Hemming D, White M, Vardoulakis S, Fleming LE (2017) Pollen exposure and hospitalization due to asthma exacerbations: daily time series in a European city. Int J Biometeorol 61(10): $1837-1848$

Saravanabhavan G, Walker M, Guay M, Aylward L (2014) Urinary excretion and daily intake rates of diethyl phthalate in the general Canadian population. Sci Total Environ 500:191-198

Sordillo JE, Kelly R, Bunyavanich S, McGeachie M, Qiu W, CroteauChonka DC, Soto-Quiros M, Avila L, Celedón JC, Brehm JM, Weiss ST, Gold DR, Litonjua AA (2015) Genome-wide expression profiles identify potential targets for gene-environment interactions in asthma severity. J Allergy Clin Immunol 136(4):885-892

Surdu S, Montoya LD, Tarbell A, Carpenter DO (2006) Childhood asthma and indoor allergens in Native Americans in New York. Environ Health 5(1):22

Teitelbaum SL, Britton JA, Calafat AM, Ye X, Silva MJ, Reidy JA, Galvez MP, Brenner BL, Wolff MS (2008) Temporal variability in urinary concentrations of phthalate metabolites, phytoestrogens and phenols among minority children in the United States. Environ Res 106(2):257-269

Tsai M-J, Kuo P-L, Ko Y-C (2012) The association between phthalate exposure and asthma. Kaohsiung J Med Sci 28(7):S28-S36

Varshavsky JR, Morello-Frosch R, Woodruff TJ, Zota AR (2018) Dietary sources of cumulative phthalates exposure among the US general population in NHANES 2005-2014. Environ Int 115:417-429

Vernet C, Pin I, Giorgis-Allemand L, Philippat C, Benmerad M, Quentin J, Calafat AM, Ye X, Annesi-Maesano I, Siroux V, Slama R, the EDEN Mother-Child Cohort Study Group (2017) In utero exposure to select phenols and phthalates and respiratory health in five-yearold boys: a prospective study. Environ Health Perspect 125(9): 097006

Wang IJ, Karmaus WJJ, Chen S-L, Holloway JW, Ewart S (2015) Effects of phthalate exposure on asthma may be mediated through alterations in DNA methylation. Clin Epigenetics 7(1):27

Wang B, Liu F, Dong J, You M, Fu Y, Li C, Lu Y, Chen J (2018) Maternal exposure to environmental DEHP exacerbated OVA-induced asthmatic responses in rat offspring. Sci Total Environ 615:253-261

Whyatt RM, Perzanowski MS, Just AC, Rundle AG, Donohue KM, Calafat AM, Hoepner LA, Perera FP, Miller RL (2014) Asthma in inner-city children at 5-11 years of age and prenatal exposure to phthalates: the Columbia Center for Children's Environmental Health Cohort. Environ Health Perspect 122(10):1141-1146

Wijga A, Tabak C, Postma DS, Kerkhof M, Wieringa MH, Hoekstra MO, Brunekreef B, de Jongste JC, Smit HA (2011) Sex differences in asthma during the first 8 years of life: the prevention and incidence of asthma and mite allergy (PIAMA) birth cohort study. J Allergy Clin Immunol 127(1):275-277

Publisher's note Springer Nature remains neutral with regard to jurisdictional claims in published maps and institutional affiliations. 